\title{
miR-299-5p promotes cell growth and regulates G1/S transition by targeting p21Cip1/Waf1 in acute promyelocytic leukemia
}

\author{
SHUN-QUAN WU, LANG-HUI ZHANG, HAO-BO HUANG, YA-PING LI, WEN-YAN NIU and RONG ZHAN \\ Fujian Institute of Hematology, Affiliated Union Hospital of Fujian Medical University, \\ Fujian Provincial Key Laboratory on Hematology, Fuzhou, Fujian 350001, P.R. China
}

Received March 24, 2015; Accepted April 15, 2016

DOI: $10.3892 / \mathrm{ol} .2016 .4621$

\begin{abstract}
MicroRNAs (miRs) are often located in genomic breakpoint regions and are hypothesized to be important regulators involved in the regulation of critical cell processes, including cell apoptosis, proliferation and differentiation. miR-299 has been reported to be upregulated in acute promyelocytic leukemia (APL); however, the function and mechanistic role of miR-299 in APL remains unknown. The present study demonstrated mir-299 significantly induced cell growth and cell cycle progression at the G1/S transition in APL cells. Notably, the present study revealed that miR-299-5p induces these effects, whereas miR-299-3p does not. Additional studies demonstrated that in APL cells the tumor suppressor p21Cip1/Waf1 is a downstream target of miR-299; miR-299 binds directly to the 3' untranslated region of $\mathrm{p} 21 \mathrm{Cip} 1 / \mathrm{Waf} 1$, and reduces protein, but not mRNA, levels of p21Cip1/Waf1. The present findings demonstrate that miR-299 exerts growth-promoting effects in APL cells through the suppression of p21Cip1/Waf1. Overall, the present study demonstrates that $\mathrm{p} 21 \mathrm{Cip} 1 / \mathrm{Waf} 1$ is a direct functional target of miR-299 in APL.
\end{abstract}

\section{Introduction}

MicroRNAs (miRs) are endogenous, small non-coding RNAs that have been identified as post-transcriptional regulators of gene expression. miRs exert their function by binding to the 3' untranslated regions (UTRs) of target mRNAs, which prevent mRNA translation or cause target degradation, leading to a downregulation in the expression of their downstream target genes (1). Accumulating evidence reveals that miRs are crucial in a variety of cellular and biological processes. In addition, deregulation of miRs has been demonstrated in numerous

Correspondence to: Professor Rong Zhan, Fujian Institute of Hematology, Affiliated Union Hospital of Fujian Medical University, Fujian Provincial Key Laboratory on Hematology, 29 Xin Quan Road, Fuzhou, Fujian 350001, P.R. China

E-mail: deanzhanrong@qq.com

Key words: miR-299, p21Cip1/Waf1, acute promyelocytic leukemia types of human diseases, including cancer (2). During tumor development and progression, miRs function as oncogenes or tumour suppressor genes (3). Gene expression profiling studies have revealed that miR expression signatures are associated with specific tumour subtypes and clinical outcomes (4). In certain clinical circumstances, miR profiling may be superior to mRNA profiling to classify tumor subtypes and provide a prognosis for patients $(5,6)$. Additional studies have indicated that numerous cancer-associated miRs are frequently identified at genomic breakpoint regions (3).

Acute promyelocytic leukemia (APL) is a subtype of acute myeloid leukemia (AML), and is characterized by a reciprocal translocation that involves chromosomes 15 and 17. The specific chromosome translocation $\mathrm{t}(15 ; 17)(\mathrm{q} 24 ; \mathrm{q} 11-12)$ results in the fusion of retinoic acid receptor- $\alpha(\operatorname{RAR} \alpha)$ gene on chromosome 17 with promyelocytic leukemia (PML) gene on chromosome 15 , subsequently contributing to a maturation arrest at the promyelocytic stage of development and leukemogenesis (7). The remission rate and disease-free survival time are usually higher in patients with APL compared with patients with other subtypes of AML, and relapse remains an important factor affecting the long term disease-free survival of patients with APL (8). Consequently, the molecular pathogenesis of APL is complicated and requires elucidation. Previous studies have investigated the genes and proteins involved in the development and progression of APL, and studies have revealed that miRs are important in leukemia with APL progression, which have led to novel diagnostic and therapeutic methodologies (9-11). miR-299 locating at $14 \mathrm{q} 32$ has been reported to be upregulated in APL (12). However, little is known concerning the potential functions and exact mechanistic roles of miR-299 in APL. In a previous study conducted by the present authors, $28 \mathrm{miRs}$, including miR-299-5p, were demonstrated to modulate p21Cip1/Waf1 expression by directly targeting its 3'UTR (13). Therefore, the present study hypothesizes that an overexpression of miR-299 contributes to APL progression by targeting p21Cip1/Waf1 post-transcriptionally.

The present study demonstrated that miR-299 was overexpressed in APL cells, and its expression significantly promoted APL cell growth and cell cycle progression at G1/S transition, primarily involving miR-299-5p, but not miR-299-3p. Additional experiments revealed that miR-299 downregulates protein, but not mRNA, levels of p21Cip1/Waf1. Overall, the 
present results indicate that $\mathrm{p} 21 \mathrm{Cip} 1 / \mathrm{Waf} 1$ is a direct functional target of miR-299 in APL.

\section{Materials and methods}

Patients samples. A total of 45 patients with newly diagnosed APL (25 males and 20 females; median age, 35 years; age range, 14-65 years) were recruited from the Department of Hematology, Affiliated Union Hospital of Fujian Medical University (Fuzhou, China). The diagnosis of APL was based on the 2008 World Health Organization criteria (14). In total, 18 healthy donors (10 males and 8 females; median age, 28 years; age range, 16-62 years) were used as controls for normalization. Written informed consent was obtained from all patients.

RNA extraction and quantitative polymerase chain reaction ( $q P C R$ ). Mononuclear cells (MNCs) were separated from bone marrow or whole peripheral blood from the patients and healthy donors using Ficoll-Hypaque density gradient centrifugation (Inno-Train Diagnostik GmbH, Kronberg im Taunus, Germany). Total RNA was extracted from MNCs and human promyelocytic leukemia NB4 and HL-60 cells (American Type Culture Collection, Manassas, VA, USA) infected with miR-299-5p/3p and anti-miR-299-5p/3p, using TRIzol reagent (Invitrogen $^{\mathrm{TM}}$; Thermo Fisher Scientific, Inc., Waltham, MA, USA). To determine miR expression, total RNA ( $1 \mu \mathrm{l} /$ sample) was reverse-transcribed using miR-specific stem-loop reverse transcription (RT) primers, reverse transcriptase, RT buffer, dNTPs and an RNase inhibitor, according to the manufacturer's protocol (TaqMan ${ }^{\circledR}$ MicroRNA Reverse Transcription kit; Applied Biosystems ${ }^{\mathrm{TM}}$; Thermo Fisher Scientific, Inc.). qPCR was performed using an Applied Biosystems ${ }^{\mathrm{TM}}$ StepOnePlus ${ }^{\mathrm{TM}}$ Real-Time PCR System (Thermo Fisher Scientific, Inc.). The 20- $\mu 1$ reaction system contained the corresponding complementary DNA $(2 \mu \mathrm{l})$, miRNA-specific TaqMan ${ }^{\circledR} \operatorname{primers}(1 \mu \mathrm{l})$, TaqMan ${ }^{\circledR}$ Universal PCR Master Mix $(10 \mu \mathrm{l})$ and $\mathrm{ddH}_{2} \mathrm{O}(7 \mu \mathrm{l})$ (Applied Biosystems ${ }^{\mathrm{TM}}$; Thermo Fisher Scientific, Inc.). The PCR conditions were $95^{\circ} \mathrm{C}$ for $10 \mathrm{~min}$, followed by 50 cycles at $95^{\circ} \mathrm{C}$ for $15 \mathrm{sec}$ and $60^{\circ} \mathrm{C}$ for $1 \mathrm{~min}$. RNU6B was used as an endogenous housekeeping control for data normalization of miR levels. The endogenous mRNA levels of p21 were detected using the SYBR Green PCR Master Mix kit, according to the manufacturer's protocol (Takara Bio, Inc., Otsu Japan). The RT reactions contained $500 \mathrm{ng}$ total RNA extracted from the samples, $2 \mu 15 \mathrm{X}$ PrimeScript ${ }^{\mathrm{TM}}$ Buffer (Takara Bio, Inc.), $0.5 \mu 11 \mathrm{X}$ PrimeScript ${ }^{\mathrm{TM}}$ RT Enzyme Mix I (Takara Bio, Inc.) and $0.5 \mu \mathrm{l}$ oligo(dT) primer. The $10-\mu 1$ reactions were incubated for $42 \mathrm{~min}$ at $37^{\circ} \mathrm{C}$, followed by $30 \mathrm{sec}$ of incubation at $85^{\circ} \mathrm{C}$ and subsequent exposure to $4^{\circ} \mathrm{C}$. The PCR primers (Invitrogen; Thermo Fisher Scientific, Inc.) were as follows: p21, forward 5'-TGATTAGCAGCGGAACAAG-3' and reverse 5'-AAACAGTCCAGGCCAGTATG-3'; $\beta$-actin, forward 5'-TTGTTACAGGAAGTCCCTTGCC-3' and reverse 5'-ATG CTATCACCTCCCCTGTGTG-3'. The comparative threshold cycle $(\mathrm{Cq})$ method was used to measure the relative changes in expression; $2^{-\Delta \Delta C t}$ represents the fold-change in expression (15).

Cell culture. Human embryonic kidney (HEK)-293T cells were obtained from the American Type Culture Collection and cultured in Dulbecco's modified Eagle's medium (Invitrogen; Thermo Fisher Scientific, Inc.) with $10 \%$ fetal bovine serum (FBS; Invitrogen; Thermo Fisher Scientific, Inc.). Human promyelocytic leukemia HL-60 and NB4 cells were cultured in RPMI-1640 (Invitrogen; Thermo Fisher Scientific, Inc.) with $10 \% \mathrm{FBS}, 50 \mathrm{U} / \mathrm{ml}$ penicillin and $50 \mu \mathrm{g} / \mathrm{ml}$ streptomycin (Invitrogen; Thermo Fisher Scientific).

Lentivirus production and infection. Pri-miR-299 sequences were amplified and cloned into the pWPXL lentiviral vector (a gift from Professor Didier Trono, School of Life Sciences, Ecole Polytechnique Fédérale de Lausanne, Lausanne, Switzerland). Briefly, a 700 bp fragment carrying pri-miR-299 was amplified from human genomic DNA by the Phusion ${ }^{\circledR}$ High-Fidelity DNA Polymerase enzyme (New England Biolabs, Inc., Ipswich, MA, USA) using the following PCR primers: Forward 5'-CGGGATCCATGACGTGGTTGACT ACGC-3' and reverse 5'-GCGTCGACTCTTCAATTACTC CAGAGG-3' (Invitrogen; Thermo Fisher Scientific, Inc.). The amplified fragment was first cloned into a pMD-18T vector (Takara Bio Inc.) with fusion green fluorescent protein expression and then subcloned (BamHI + EcoRV; Takara Bio Inc.) into a pWPXL lentivirus vector. The pWPXL vectors were transfected into HEK-293T cells with the packaging plasmid psPAX2 and the VSV-G envelope plasmid pMD2.G (obtained from Dr Didier Trono) using Lipofectamine ${ }^{\circledR} 2000$ reagent (Invitrogen $^{\mathrm{TM}}$; Thermo Fisher Scientific, Inc.). Cell supernatants were collected at $48 \mathrm{~h}$ post-transfection and passed through a $0.22-\mathrm{mm}$ filter. The titer of purified virus was $2.0 \times 10^{8} \mathrm{IU} / \mathrm{ml}$. In total, $1 \times 10^{5} \mathrm{NB} 4$ and HL-60 cells were infected with $1 \times 10^{6}$ recombinant lentivirus-transducing units plus $6 \mu \mathrm{g} / \mathrm{ml}$ polybrene (Sigma-Aldrich, St. Louis, MO, USA).

Cell proliferation. Cell proliferation was measured using cell counting kit-8 (CCK-8) assay (Dojindo Molecular Technologies, Inc., Kumamoto, Japan). In brief, 4,000 cells were plated into each well of a 96-well plate and $10 \mu \mathrm{l}$ CCK- 8 solution was added to $90 \mu \mathrm{l}$ culture medium. The cells were subsequently incubated for $2 \mathrm{~h}$ at $37^{\circ} \mathrm{C}$ and optical density was measured at 450 and $650 \mathrm{~nm}$ using a microplate reader (ELx808; Bio-Tek Instruments, Inc., Winooski, VT, USA). Three independent experiments were performed.

Fluorescence-activated cell sorting (FACS). Cells were collected and fixed in ice-cold $70 \%$ ethanol overnight. The fixed cells were washed with phosphate-buffered saline (PBS) and stained with a freshly-prepared solution containing $25 \mu \mathrm{g} / \mathrm{ml}$ propidium iodide (Sigma-Aldrich), $10 \mu \mathrm{g} / \mathrm{ml}$ RNaseA (Sigma-Aldrich), $0.05 \mathrm{mM}$ ethylene diamine (Sigma-Aldrich) and $0.2 \%$ Triton X-100 tetra-acetic acid (Sigma-Aldrich) in PBS for $30 \mathrm{~min}$ in the dark. For each sample, $\geq 20,000$ cells were analyzed using FACS cytometry (Epics Altra; Beckman Coulter, Inc., Brea, CA, USA) and Multicycle AV for Windows 5.0 (Phoenix Flow Systems, Inc., San Diego, CA, USA).

Oligonucleotide transfection. miR-299-5p and miR-299-3p mimics and control were synthesized by Genepharma Co., Ltd. (Shanghai, China). The sequences were as follows: miR-229-5p mimic, 5'-UGGUUUACCGUCCCACAUACAU-3'; miR-229-3p mimic, 5'-UAUGUGGGAUGGUAAACCGCUU-3'; and 
negative control, 5'-UUCUCCGAACGUGUCACGUTT-3'. miR-299-3p and miR-299-5p inhibitors (2'-O-methyl modification) were synthesized by Guangzhou RiboBio Co., Ltd. (Guangzhou, China). miR-299-5p/3p and anti-miR-299-5p/3p were transfected into NB4 and HL-60 cells. Oligonucleotide transfection was performed by using Lipofectamine ${ }^{\circledR} 2000$ transfection reagent (Invitrogen; Thermo Fisher Scientific, Inc.) according to the manufacturer's protocol.

Luciferase reporter constructs and luciferase assay. The wild-type and mutant 3'UTR of p21Cip1/Waf1 were cloned downstream of a cytomegalovirus (CMV) promoter-driven firefly luciferase cassette in a pCDNA3.0 vector (Thermo Fisher Scientific, Inc.). The primers were as follows: p21Cip1/Waf1 wild-type, forward 5'-AGTGGACGTTCCCCGAGTT-3' and reverse 5'-TCCCAAAAGCCCATTTATT-3'; p21Cip1/Waf1 mutant, forward 5'-CTAGAAAGAAGATGTCCCCCATCA TATACCCCTAAC-3' and reverse 5'-GATGGGGGACATCTT CTTTCTAGGAGGGAGACACTG-3' (Invitrogen; Thermo Fisher Scientific, Inc.). For the luciferase assay, HL-60 cells were cultured in 24-well plates and cotransfected with $20 \mathrm{pmol}$ of RNA (negative control, miR-299-5p or miR-299-3p mimics), $200 \mathrm{ng}$ luciferase reporter construct and $20 \mathrm{ng}$ pRL-CMV Renilla luciferase reporter construct (Promega Corporation, Madison, WI, USA) using Lipofectamine 2000 transfection reagent according to the manufacturer's protocol. After $48 \mathrm{~h}$, luciferase activity was measured using the Dual-Luciferase ${ }^{\circledR}$ Reporter Assay System (Promega Corporation, Madison, WI, USA).

Western blot analysis. Proteins were separated on 12\% sodium dodecyl sulfate-polyacrylamide gel electrophoresis and then transferred to a nitrocellulose membrane (Bio-Rad Laboratories, Inc., Hercules, CA, USA). The membrane was blocked with 5\% non-fat milk and incubated with mouse anti-p21Cip1/Waf1 monoclonal antibody (dilution, 1:1,000; catalog no., DCS60; Cell Signaling Technology, Inc., Danvers, MA, USA) and rabbit polyclonal anti- $\beta$-actin (dilution, 1:1,000; catalog no., ab119716; Abcam, Cambridge, MA, USA). After the membranes were washed, they were incubated for $1 \mathrm{~h}$ at room temperature with mouse anti-rabbit (catalog no., bs-0295M; dilution, 1:1,000; Bioss Inc., Woburn, MA, USA) and rabbit anti-mouse (catalog no. bs-0296R; dilution, 1:1,000; Bioss Inc.) immunoglobulin G secondary antibodies. The proteins were visualized and quantified using Pierce ${ }^{\mathrm{TM}}$ ECL Western Blotting Substrate (Thermo Fisher Scientific, Inc.).

Statistical analysis. Statistical analyses were performed using GraphPad Prism version 5.0 software (GraphPad Software, Inc., La Jolla, CA, USA). The results are presented as the mean \pm standard error of the mean. The data were subjected to two-tailed Student's t-test or one-way analysis of variance when more than two groups were compared. $\mathrm{P}<0.05$ was considered to indicate a statistically significant difference.

\section{Results}

Increased expression of miR-299 promotes APL cell growth and cell cycle G1/S transition. In order to investigate the function of miR-299 in APL, a lentivirus vector cloned with
miR-299 was constructed, and two stable APL cell lines with lentivirus transduction were established: NB4-299 and HL-60-299. Cell proliferation assays revealed that an increased expression of miR-299 lead to a significant increase in cell growth of NB4-299 and HL-60-299 cells compared with vector control cells subsequent to 3 and 4 days of growth (Fig. 1A and B; P<0.05). Since, miR-299 promotes APL cell proliferation, the effect that miR-299 has on APL cell cycle progression was investigated. There was a significant reduction in the number HL-60-299 and NB4-299 cells in the G1 phase and a clear increase in cells in the $\mathrm{S}$ phase compared with the vector control cells (Fig. $1 \mathrm{C}$ and $\mathrm{D} ; \mathrm{P}<0.05$ ). Therefore, miR-299 induced the growth of APL cells, possibly by enhancing cell cycle progression at the $\mathrm{G} 1 / \mathrm{S}$ transition.

miR-299-5p, but not miR-299-3p, promotes the growth and cell cycle progression of APL cells. According to miRBase sequences (www.mirbase.org/), miR-299 consists of two mature sequences: miR-299-5p and miR-299-3p. Consequently, to additionally investigate which mature sequence is involved in APL cell growth, synthesized miR mimics of miR-299-5p and miR-299-3p were introduced into NB4 cells, which did not express miR-299, but did express PML/RAR $\alpha$. In addition, in a previous study, an anti-miR mimic of miR-299-5p and miR-299-3p were introduced into HL-60 cells, which did not express PML/RAR $\alpha$, but did have a relatively high expression of miR-299 (12). The present results demonstrated that miR-299-5p, but not miR-299-3p, promoted APL cell growth and led to a significant increase in cell cycle arrest at G1 in NB4 cells (Fig. 2A and B). Additionally, a significant decrease in cell growth and increased cell cycle arrest at G1 was observed following silencing of miR-299-5p in HL60 cells compared with control cells $(\mathrm{P}<0.05)$, whereas miR-299-3p silencing had no significant effect (Fig. 2C and D). Overall, these results reveal that APL cell proliferation and cell cycle progression is enhanced by miR-299-5p, but not miR-299-3p.

miR-299-5p downregulates p21Cip1/Waf1 expression by directly targeting the $3^{\prime} U T R$. It is well known that miRs is functions by causing a downregulation in the expression of downstream target genes. The present authors previously demonstrated that $\mathrm{p} 21 \mathrm{Cip} 1 /$ Waf1 is directly targeted by 28 miRs in HEK-293 cells, using a high-throughput luciferase reporter screen (13). Notably, miR-299-5p was one of the $28 \mathrm{miRs}$ identified. Therefore, to determine whether miR-299-5p exerts its function by downregulating the expression of p21Cip1/Waf1 through direct binding to its 3'UTR, full-length fragments of p21Cip1/Waf1 mRNA 3'UTR (either wild-type or mutant-type) were constructed and inserted downstream of the luciferase reporter gene. For the luciferase assays, either the miR-299-5p or the miR-299-3p mimic was cotransfected with various luciferase 3' UTR constructs in NB4 cells.

The present results revealed that the relative luciferase activity with the wild-type 3'UTR of p21Cip1/Waf1 was decreased by expression of miR-299-5p, but not miR-299-3p (Fig. 3A; $\mathrm{P}=0.034$ ). Additional analysis revealed that this regulation was sequence specific, since the relative luciferase activity did not decrease as clearly in UTRs with mutant-binding sites compared with wild-type-binding sites 
A

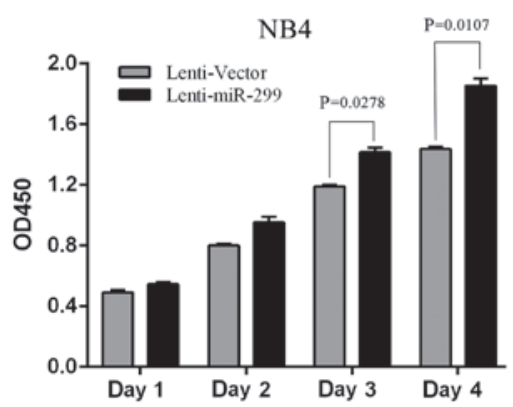

C

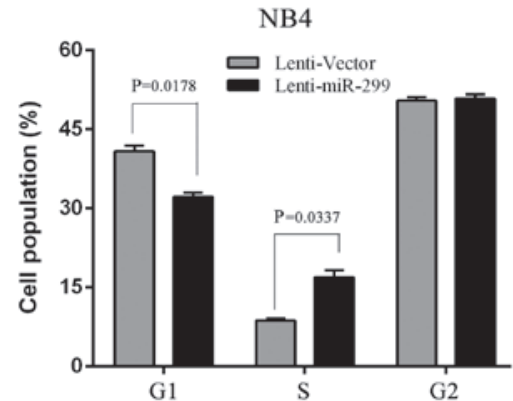

B

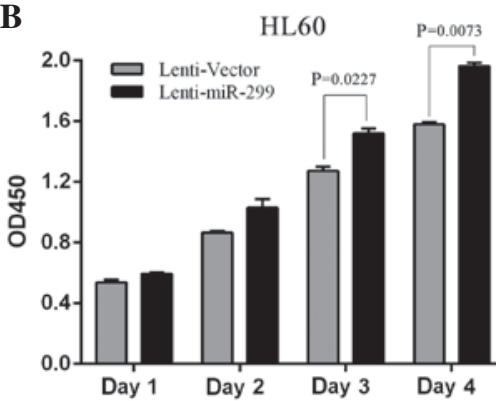

D

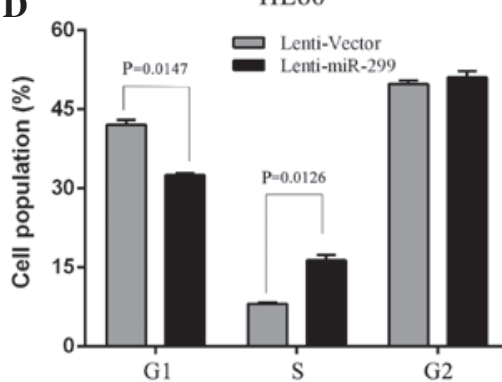

Figure 1. Increased expression of miR-299 promotes cell growth and cell cycle G1/S transition. (A and B) Cell proliferation assays and (C and D) fluorescence-activated cell sorting of human acute promyelocytic leukemia NB4 and HL-60 cells was performed following infection with miR-299-expressing or control lentivirus. Results are presented as the mean \pm standard error of the mean of three experiments. miR, microRNA; lenti, lentivirus; OD, optical density.

A

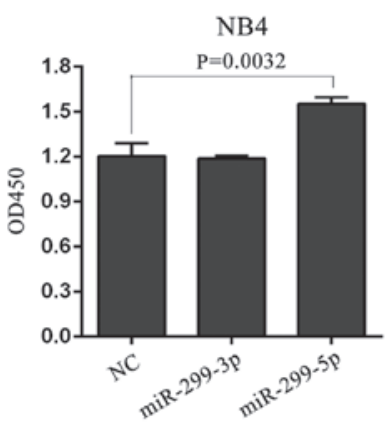

C

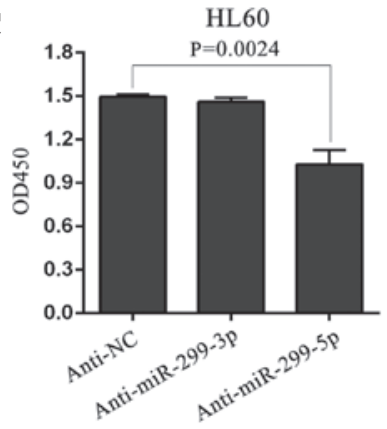

B

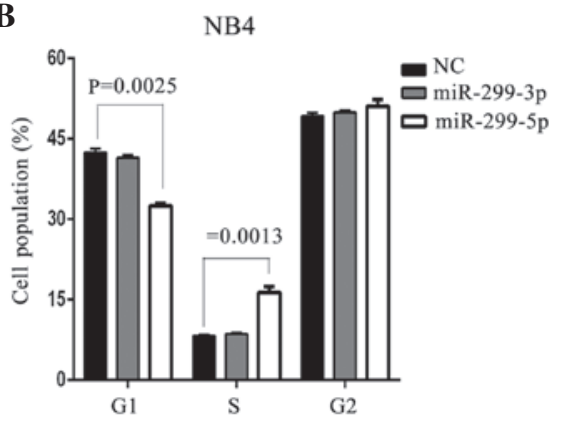

D

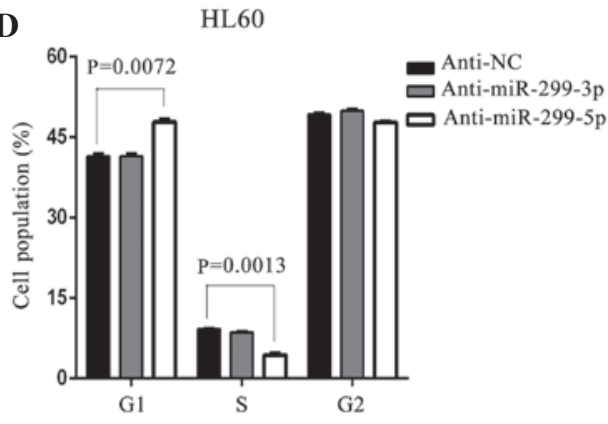

Figure 2. miR-299-5p, but not miR-299-3p, promotes the growth and cell cycle progression of human acute promyelocytic leukemia cells. (A) Cell proliferation assay and (B) FACS of NB4 cells transfected with miR-299-5p or miR-299-3p mimics or NC. (C) Cell proliferation assay and (D) FACS of HL60 cells transfected with anti-miR-299-5p or miR-299-3p mimics or anti-NC. The results are representative of at least three independent experiments. Error bars represent the standard error of the mean. miR, microRNA; NC, negative control; OD, optical density; FACS, fluorescence-activated cell sorting.

(Fig. 3A). In concordance with these results, a clear decrease in endogenous p21Cip1/Waf1 protein was observed in NB4 and HL-60 cells following transfection with miR-299-expressing lentivirus. Following transfection with the miR-299-5p mimic, p21Cip1/Waf1 protein expression was significantly decreased in NB4 cells, whereas no clear alterations were observed following transfection with miR-299-3p mimic (Fig. 3B).
Furthermore, inhibition of miR-299-5p, but not miR-299-3p, significantly increased the expression levels of p21Cip1/Waf1 protein in HL60 cells (Fig. 3B). Notably, overexpression of miR-299-5p or miR-299-3p did not affect the expression level of p21Cip1/Waf1 mRNA (Fig. 3C). Overall, these results suggest that miR-299-5p downregulates p21Cip1/Waf1 expression post-transcriptionally by directly targeting its 3 'UTR. 
A

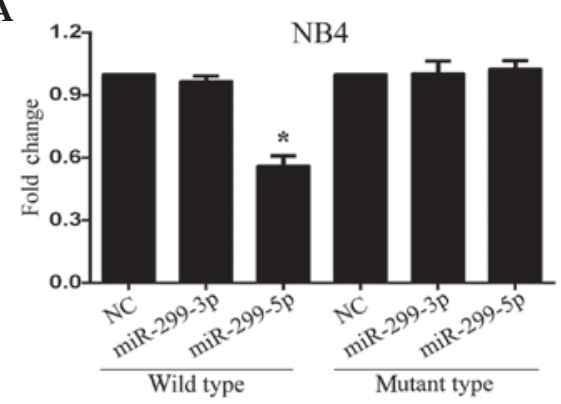

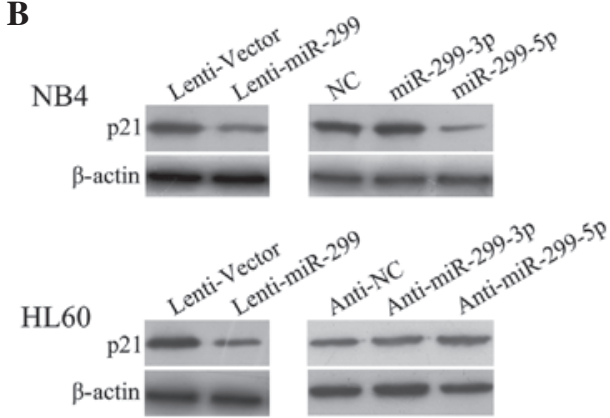

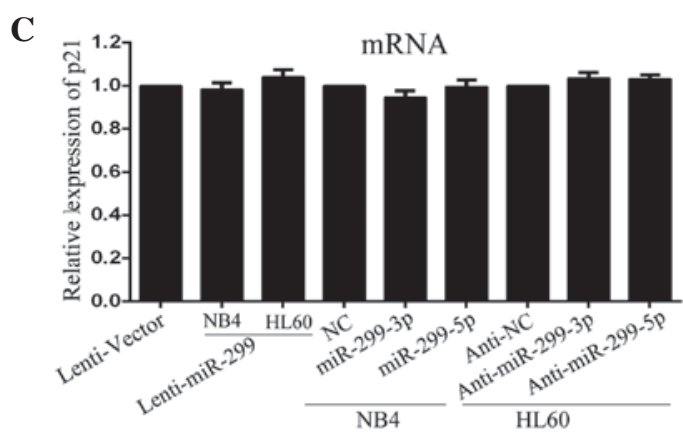

Figure 3. miR-299-5p downregulates endogenous p21Cip1/Waf1 expression by directly targeting its 3'UTR in human acute promyelocytic leukemia cells. (A) Luciferase activity assays of luciferase reporters with wild-type or mutant-type p21Cip1/Waf1 3'UTRs were performed following cotransfection with miR-299-5p or miR-299-3p mimics or NC in NB4 cells. Luciferase activity was normalized to Renilla luciferase activity. ${ }^{*} \mathrm{P}<0.05$ vs. NC. (B) Protein and (C) mRNA expression of $\mathrm{p} 21 \mathrm{Cip} 1 /$ Waf1 were investigated by western blot analysis and quantitative polymerase chain reaction analysis, respectively, following transfection with miR-299-5p or miR-299-3p mimics or NC in NB4 cells, and anti-miR-299-5p or anti-miR-299-3p mimics or anti-NC in HL60 cells. $\beta$-actin served as an internal control for western blot analysis. Error bars represent standard error of the mean. miR, microRNA; UTR, untranslated region; NC, negative control; lenti, lentivirus.

A

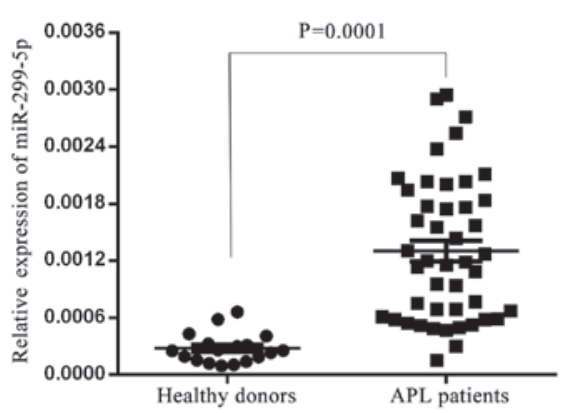

C
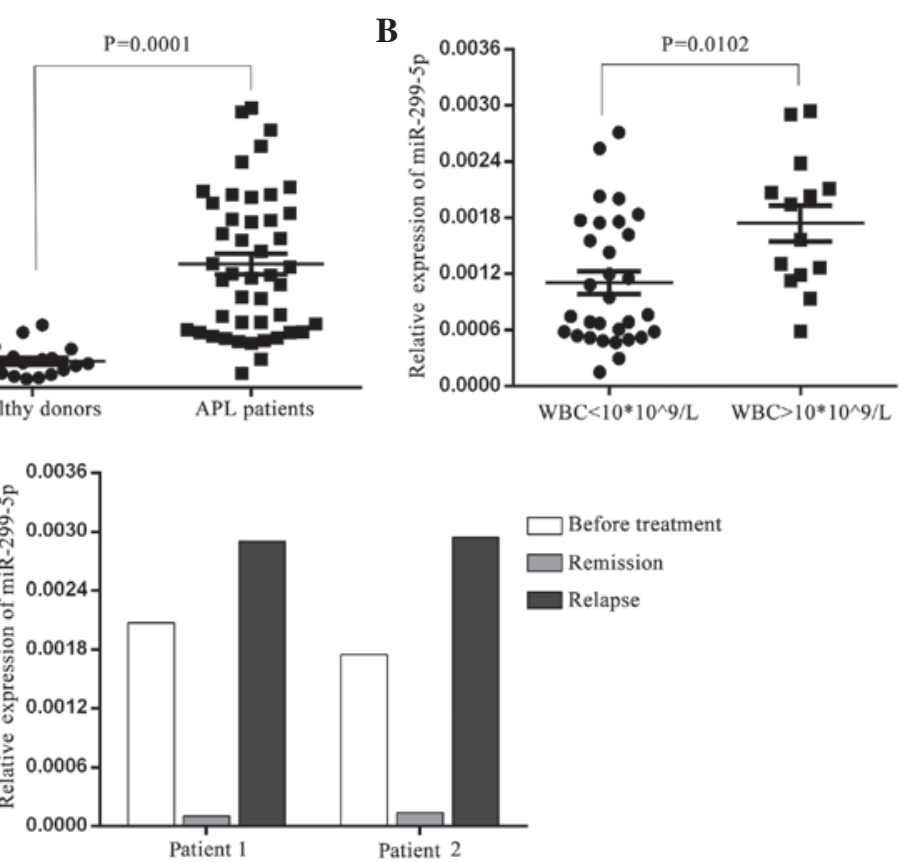

Figure 4. Expression levels of miR-299-5p in patients with APL. (A) Expression levels of miR-299-5p in patients with APL and healthy controls. (B) Expression levels of miR-299-5p in high (WBC count, $>10 \times 10^{9} / 1$ ) and low-risk (WBC count, $\leq 10 \times 10^{9} / 1$ ) patients with APL. (C) Expression levels of miR-299-5p in two patients following remission and relapse. miR, microRNA; APL, acute promyelocytic leukemia; WBC, white blood cells.

miR-299-5p is overexpressed in patients with APL. Finally, the expression levels of miR-299-5p and miR-299-3p were determined in bone marrow MNCs from newly diagnosed APL patients and healthy donors using TaqMan qPCR. The results revealed that miR-299-5p was significantly increased in APL patients compared to healthy donors (Fig. 4A; $\mathrm{P}<0.01$ ). miR-299-3p was not detected in APL patients (data not shown). Prior to treatment, APL patients were divided into high [white 
blood cell (WBC) count, $\left.>10 \times 10^{9} / 1\right]$ and low-risk (WBC count, $\left.\leq 10 \times 10^{9} / 1\right)$ groups. Subsequently, miR-299-5p expression was analyzed in the high-risk and low-risk groups, and the results revealed that miR-299-5p expression was significantly higher in MNCs from high-risk APL patients compared with low-risk patients (Fig. 4B; P<0.05). Furthermore, miR-299-5p expression was determined in certain patients following treatment remission and relapse. These patients were treated with all trans-retinoic acid (ATRA; $45 \mathrm{mg} / \mathrm{m}^{2}$ per dose) and remained on ATRA for $\sim 30$ days following the attainment of complete clinical remission. After discontinuing ATRA treatment, 3 cycles of cytarabine and idarubicin (or daunorubicin) were administered as consolidation therapy. As shown in Fig. 4C, miR-299-5p expression decreased following remission and increased following relapse. Taken together, these results demonstrate that the expression levels of miR-299-5p are increased in APL patients; therefore, miR-299-5p may serve as a potential prognostic indicator for APL.

\section{Discussion}

miR-299 consists of two mature sequences, miR-299-5p and miR-299-3p, and is located at 14q32.31, which encodes 40 miRs (16). Previously, it was reported that miR-299-5p was downregulated in spheroid-derived breast cancer cells, resulting in an increased expression of osteopontin (17). Another study revealed that miR-299-5p is involved in the regulation of hematopoietic progenitor fate by modulating megakaryocytic-granulocytic from erythroid-monocytic differentiation (18). In addition, a dysregulation of miR-299-5p is observed in primary biliary cirrhosis (19) and prostate cancer (16). miR-299 expression is upregulated in APL patient samples with a $t(15 ; 17)$ translocation, but is not identified in NB4 cells with a $\mathrm{t}(15 ; 17)$ translocation (12). However, there is little information concerning the function of miR-299-5p.

The present study demonstrated that ectopic expression of miR-299 promotes cell growth and cell cycle progression at the G1/S transition in APL cells. As it is known, miR-299 consists of two mature sequences, miR-299-3p and miR-299-5p; therefore, the miR-299 sequence involved in APL cell growth remains to be elucidated. Consequently, the present study overexpressed miR-299-5p and miR-299-3p in HL-60 and NB4 cells by introducing synthesized miR mimics. The present results revealed that an overexpression of miR-299-5p promoted APL cell growth and resulted in a significant increase in cell cycle arrest at G1, whereas an overexpression of miR-299-3p did not. These results indicate that miR-299 enhances APL cell proliferation and cell cycle progression via miR-299-5p. In addition, the present study identified that miR-299-5p was overexpressed in APL patients and, therefore, may be used as a predictor of disease conditions, unlike miR-299-3p.

Downstream target genes are essential when miRs exert their function (20). The present authors previously identified, using high-throughput screening, $28 \mathrm{miRs}$, including miR-299-5p, which regulated p21Cip1/Waf1 expression by directly targeting its 3'UTR (13). The present study also identified p21Cip1/Waf1 as a direct functional downstream target of miR-299-5p in APL cells. One potential target site of miR-299-5p was identified in p21Cip1/Waf1 3'UTR, and cotransfection of miR-299-5p with wild-type 3'UTR led to a decrease of the relative luciferase activity. However, when the potential target site was mutated, luciferase activity increased to a level similar to that observed with the control vector. In addition, endogenous $\mathrm{p} 21 \mathrm{Cip} 1 /$ Waf1 protein levels were downregulated by miR-299-5p in APL cells. Notably, the expression level of p21Cip1/Waf1 mRNA did not alter following an overexpression of miR-299-5p. Therefore, miR-299-5p possibly regulates $\mathrm{p} 21 \mathrm{Cip} 1 /$ Waf1 expression post-transcriptionally.

In conclusion, the present study has demonstrated for the first time, to the best of our knowledge, that miR-299, primarily miR-299-5p, exerts growth-promoting effects in APL cells by downregulating the expression of the tumor suppressor p21Cip1/Waf1. The present results suggest an oncogenic function and a potential therapeutic application for miR-299 in APL.

\section{Acknowledgements}

The authors are grateful to Professor Didier Trono for providing the pWPXL, psPAX2 and pMD2.G lentivirus plasmids. This study was supported by the National Natural Science Foundation of China (grant no. 81201872), Natural Science Foundation of Fujian Province (grant nos. 2010J01164 and 2013J01308) and Foundation of Fujian Key Laboratory of Hematology (grant no. 2009J1004).

\section{References}

1. Bartel DP: MicroRNAs: Genomics, biogenesis, mechanism and function. Cell 116: 281-297, 2004.

2. Ambros V: The functions of animal microRNAs. Nature 431: 350-355, 2004

3. Garzon R, Calin GA and Croce CM: MicroRNAs in cancer. Annu Rev Med 60: 167-179, 2009.

4. Zhong X, Coukos G and Zhang L: miRNAs in human cancer. Methods Mol Biol 822: 295-306, 2012.

5. Bartel DP: MicroRNAs: Target recognition and regulatory functions. Cell 136: 215-233, 2009.

6. He L and Hannon GJ: MicroRNAs: Small RNAs with a big role in gene regulation. Nat Rev Genet 5: 522-531, 2004.

7. Avvisati G, ten Cate JW and Mandelli F: Acute promyelocytic leukaemia. Br J Haematol 81: 315-320, 1992.

8. Mathews V, George B, Lakshmi KM, Viswabandya A, Bajel A, Balasubramanian P, Shaji RV, Srivastava VM, Srivastava A and Chandy M: Single-agent arsenic trioxide in the treatment of newly diagnosed acute promyelocytic leukemia: Durable remissions with minimal toxicity. Blood 107: 2627-2632, 2006.

9. Mi S, Lu J, Sun M, Li Z, Zhang H, Neilly MB, Wang Y, Qian Z, Jin J, Zhang Y, et al: MicroRNA expression signatures accurately discriminate acute lymphoblastic leukemia from acute myeloid leukemia. Proc Natl Acad Sci USA 104: 19971-19976, 2007.

10. Georgantas RW III, Hildreth R, Morisot S, Alder J, Liu CG, Heimfeld S, Calin GA, Croce CM and Civin CI: CD34+ hematopoietic stem-progenitor cell microRNA expression and function: A circuit diagram of differentiation control. Proc Natl Acad Sci USA 104: 2750-2755, 2007.

11. Jongen-Lavrencic M, Sun SM, Dijkstra MK, Valk PJ and Löwenberg B: MicroRNA expression profiling in relation to the genetic heterogeneity of acute myeloid leukemia. Blood 111: 5078-5085, 2008.

12. Dixon-McIver A, East P, Mein CA, Cazier JB, Molloy G, Chaplin T, Andrew Lister T, Young BD and Debernardi S: Distinctive patterns of microRNA expression associated with karyotype in acute myeloid leukaemia. PLoS One 3: e2141, 2008.

13. Wu S, Huang S, Ding J, Zhao Y, Liang L, Liu T, Zhan R and He X: Multiple microRNAs modulate p21Cip1/Waf1 expression by directly targeting its 3 ' untranslated region. Oncogene 29: 2302-2308. 
14. Vardiman JW, Thiele J, Arber DA, Brunning RD, Borowitz MJ, Porwit A, Harris NL, Le Beau MM, Hellström-Lindberg E, Tefferi A and Bloomfield CD: The 2008 revision of the World Health Organization (WHO) classification of myeloid neoplasms and acute leukemia: Rationale and important changes. Blood 114: 937-951, 2009.

15. Livak KJ and Schmittgen TD: Analysis of relative gene expression data using real-time quantitative PCR and the 2(-Delta Delta C(T)) method. Methods 25: 402-408, 2001.

16. Formosa A, Markert EK, Lena AM, Italiano D, Finazzi-Agro' E, Levine AJ, Bernardini S, Garabadgiu AV, Melino G and Candi E: MicroRNAs, miR-154, miR-299-5p, miR-376a, miR-376c, miR-377, miR-381, miR-487b, miR-485-3p, miR-495 and miR-654-3p, mapped to the 14q32.31 locus, regulate proliferation, apoptosis, migration and invasion in metastatic prostate cancer cells. Oncogene 33: 5173-5182, 2014.
17. Lowery AJ, Miller N, Devaney A, McNeill RE, Davoren PA, Lemetre C, Benes V, Schmidt S, Blake J, Ball G and Kerin MJ: MicroRNA signatures predict oestrogen receptor, progesterone receptor and HER2/neu receptor status in breast cancer. Breast Cancer Res 11: R27, 2009.

18. Tenedini E, Roncaglia E, Ferrari F, Orlandi C, Bianchi E, Bicciato S, Tagliafico E and Ferrari S: Integrated analysis of microRNA and mRNA expression profiles in physiological myelopoiesis: Role of hsa-mir-299-5p in CD34+ progenitor cells commitment. Cell Death Dis 1: e28, 2010.

19. Padgett KA, Lan RY, Leung PC, Lleo A, Dawson K, Pfeiff J, Mao TK, Coppel RL, Ansari AA and Gershwin ME: Primary biliary cirrhosis is associated with altered hepatic microRNA expression. J Autoimmun 32: 246-253, 2009.

20. Krol J, Loedige I and Filipowicz W: The widespread regulation of microRNA biogenesis, function and decay. Nat Rev Genet 11: 597-610, 2010. 